\title{
Neuropeptides Amplify and Focus the Monoaminergic Inhibition of Nociception in Caenorhabditis elegans
}

\author{
Vera Hapiak, Philip Summers, Amanda Ortega, Wen Jing Law, Andrew Stein, and Richard Komuniecki \\ Department of Biological Sciences, University of Toledo, Toledo, Ohio 43606-3390
}

\begin{abstract}
Monoamines and neuropeptides interact to modulate most behaviors. To better understand these interactions, we have defined the roles of tyramine (TA), octopamine, and neuropeptides in the inhibition of aversive behavior in Caenorhabditis elegans. TA abolishes the serotonergic sensitization of aversive behavior mediated by the two nociceptive ASH sensory neurons and requires the expression of the adrenergic-like, $\mathrm{G} \alpha$-coupled, TA receptor TYRA-3 on inhibitory monoaminergic and peptidergic neurons. For example, TA inhibition requires $\mathrm{G} \alpha_{\mathrm{q}}$ and $\mathrm{G} \alpha_{\mathrm{s}}$ signaling in the peptidergic ASI sensory neurons, with an array of ASI neuropeptides activating neuropeptide receptors on additional neurons involved in locomotory decision-making. The ASI neuropeptides required for tyraminergic inhibition are distinct from those required for octopaminergic inhibition, suggesting that individual monoamines stimulate the release of different subsets of ASI neuropeptides. Together, these results demonstrate that a complex humoral mix of monoamines is focused by more local, synaptic, neuropeptide release to modulate nociception and highlight the similarities between the tyraminergic/octopaminergic inhibition of nociception in C. elegans and the noradrenergic inhibition of nociception in mammals that also involves inhibitory peptidergic signaling.
\end{abstract}

\section{Introduction}

Monoamines and neuropeptides can act independently or often in concert to mediate the nutritional modulation of a host of behavioral responses. In mammals, olfaction is used to find food and initiate feeding; conversely, food availability and nutritional status modulate olfaction (Mulligan et al., 2002; Yeomans, 2006; Aime et al., 2007). For example, neuropeptide Y transiently increases olfaction in fasted, but not fed, rats and orexin or leptin mimic the effects of fasting or satiety, respectively (Prudhomme et al., 2009; Negroni et al., 2012). Similarly, feeding behavior is influenced by $\alpha_{2}$-noradrenergic, serotonergic, and peptidergic systems (Clifton and Kennett, 2006; Magalhaes et al., 2010). In fact, monoaminergic and peptidergic signaling are extensively intertwined, and, in many disease states, including depression and chronic pain, the balance of signaling is altered (Werner and Convenas, 2010; Drago et al., 2011). In invertebrates, nutritional status also modulates olfaction and nociception. In Drosophila, olfactory preferences and feeding behavior can be modulated by both monoamines and peptides (Melcher and Pankratz, 2005; Root et al., 2011). In Caenorhabditis elegans, food availability also modulates sensory-mediated behaviors, and the circuit involved in nutritionally driven locomotory decision-making has been an-

\footnotetext{
Received March 28, 2013; revised July 8, 2013; accepted July 12, 2013.

Author contributions: V.H., P.S., and R.K. designed research; V.H., P.S., A.O., W.J.L., and A.S. performed research; V.H., P.S., and R.K. analyzed data; V.H. and R.K. wrote the paper.

This work was supported by National Institutes of Health Grant AI-145147 (R.K.) and funds from the Joan L. and Julius H. Jacobson Biomedical Professorship. We thank the C. elegans Genetics (enter and the National Bioresources Center for strains, Dr. Cori Bargmann for interesting discussion and the npr-11 (ok594) and (AIA) gcy-28.d::npr-11::gfp in npr-11 strains, and Dr. Bruce Bamber for advice and analytical tools.

The authors declare no competing financial interests.

Correspondence should be addressed to Dr. Richard W. Komuniecki, Department of Biological Sciences, University of Toledo, 2801 West Bancroft Street, Toledo, OH 43606-3390. E-mail: rkomuni@uoft02.utoledo.edu.

V. Hapiak's present address: Department of Biology and the National Center for Behavioral Genomics, Brandeis University, 415 South Street, Waltham, MA 02454.

DOI:10.1523/JNEUROSCI.1324-13.2013

Copyright $\odot 2013$ the authors $\quad 0270-6474 / 13 / 3314107-10 \$ 15.00 / 0$
}

alyzed extensively (Gray et al., 2005; Chalasani et al., 2007, 2010; Harris et al., 2010, 2011; Sengupta, 2013).

In the present study, we defined the role of nutritionally driven monoaminergic signaling in the modulation of nociceptive behavior in C. elegans, i.e., reversal initiated in response to a volatile repellant. On food, serotonin (5-HT) is released humorally and dramatically decreases the time taken to initiate aversive behavior (Chao et al., 2004; Harris et al., 2009, 2011). In contrast, off food, tyramine (TA) and octopamine (OA) abolish 5-HT stimulation (Wragg et al., 2007; Mills et al., 2012a). The receptors mediating the 5-HT stimulation and OA inhibition of ASH-mediated aversive responses describe a complex, monoamine-dependent, humorally translated, decisionmaking "circuit" (Komuniecki et al., 2012a). For example, three distinct 5-HT receptors, operating at different levels in the ASHmediated circuit, are essential for food or 5-HT stimulation (Harris et al., 2009, 2010). Similarly, OA inhibition involves multiple OA receptors that not only inhibit ASH signaling directly but also trigger the release of neuropeptides that modulate signaling from additional sensory neurons (Mills et al., 2012a). In fact, OA inhibition of aversive responses mimics the noradrenergic inhibition of nociception in mammals (Kawasaki et al., 2003; Komuniecki et al., 2012a).

The present study demonstrates that TA inhibits 5-HTstimulated aversive responses through the $\mathrm{G} \alpha_{\mathrm{q}}$-coupled TA receptor TYRA-3 and activates a global inhibitory signaling cascade that involves a complex mix of additional monoamines, including OA and dopamine (DA), and neuropeptides. Importantly, the ASI neuropeptides required for the tyraminergic or octopaminergic inhibition are distinct, suggesting that individual monoamines can stimulate the release of different ASI neuropeptides. Together, these studies highlight the complexity of TA inhibition, with TA activating a widespread signaling cascade, and suggest that signaling from a complex extrasynaptic mix of monoamines is amplified and focused by the localized synaptic release of neuropeptides to define nutritional status in the modulation of a range of sensory-mediated behaviors. 


\section{Materials and Methods}

Nematode growth and strains. General techniques for the culture and handling of worms have been described (Brenner, 1974). The N2 Bristol WT isolate of C. elegans was used for all studies. All animals were raised at $20^{\circ} \mathrm{C}$ under uncrowded conditions. Strains obtained from the Caenorhabditis Genetics Center (University of Minnesota, MN) include tyra-3(ok325), nlp-1(ok1469), nlp-1(ok1470), nlp-5(ok1981), nlp-14(tm1880), nlp-18(ok1557), c43c3.2(ok1387), co2h7.2(ok2068), t27d1.3(ok1626), c48c5.1(ok1387), t07d4.1(ok2575), fshr-1(ok778), npr10(ok1442), c49a9.7(ok1620), gnrr-1(ok238), y58g8a.4(ok1583), f35g8.1(ok527), tag-49(ok381), c56g3.1(ok1439), and f41e7.3(tm1497), f14f4.1(tm2243), nlp7(tm2984), nlp-9(tm3572), nlp-24(tm2105), npr-9(tm1652), tkr-1(tm1765), $z c 412.1$ (tm1504), c10c6.2(tm1583), t07d10.2(tm2765), w05b5.2(tm2974), y39a3b.5(tm3082), t22d1.12(tm1498), c16d6.2(tm1782), c56g3.1(tm1553), npr10(tm1568), and c25g6.5(tm4763) were received from the National BioResources Project (Tokyo Women's Medical University, Tokyo, Japan). All mutants were backcrossed with the N2 Bristol strain at least 4 times before use in assays or crosses. Mutant npr-11 (ok594) and CX8912 npr-11; kyEx1686 ( $g c y-28(d):: n p r-11:: g f p)$ animals were kindly provided by Dr. Cori Bargmann (Rockefeller University, New York, NY).

Behavioral assays. Responses to 1-octanol were assayed as described previously (Chao et al., 2004; Harris et al., 2010). All experiments used agematched, well-fed young adults grown at $20^{\circ} \mathrm{C}$ on standard nematode growth medium, seeded with Escherichia coli strain OP50. All mutant animals were outcrossed (five times) before assay, and all assays were performed in triplicate (at least three different lines assayed in three separate experiments) and double-blind to eliminate the influence of any investigator subjectivity. Data are presented as a mean \pm SE and analyzed by two-tailed Student's $t$ test.

Molecular biology and transgenesis. cDNA or genomic regions corresponding to entire coding sequences were amplified by PCR and expressed under cell-selective promoters when indicated. Selective expression was achieved using the dat-1 (1.4 kb; CEPs, ADEs, PDEs), tbh-1 (4.6 kb; RICs), gpa-4 (2.6 kb; ASI), srg-47 (0.65 kb; ASI), ttx-3 (1.5 $\mathrm{kb}$; AIYs), srg-8 (3.0 kb; ASKs), sra-9 (3.0 kb; ASKs), sro-1 (2.0 kb; ADLs), $g c y$-28.d (2.9 kb; AIAs), sra-6 (3.3 kb; ASHs, ASIs, PVQs, SPDs/Ms), flp-6 (2.0 kb; ASEs, AFDs, ASGs, PVT, I1), $g c y-5$ (3.2 kb; ASER), $g c y-6$ (0.5 kb; ASEL), and $n l p-1$ (2.5kb; AWCs, ASIs, BDUs, HSN, PHBs, four head neurons) promoters, respectively. Neuron-selective rescue and translational fusion constructs for receptor::gfp localization were created by overlap PCR fusion (Hobert, 2002). PCR products were pooled from at least three separate PCR reactions and coinjected with a selectable marker ( $m y o-3:: g f p$, unc-122::rfp or F25B3.3::gfp) and carrier DNA into C. elegans gonads by standard techniques (Kramer et al., 1990; Mello and Fire, 1995). Neuron-selective RNAi was created as described previously (Esposito et al., 2007; Harris et al., 2010; Mills et al., 2012a). At least three products were pooled, and sense and antisense transgenes were microinjected at 25-100 ng/ $\mu$ l, with $30 \mathrm{ng}$ of myo-3::gfp or F25B3.3::gfp. Multiple transgenic lines were examined for each RNAi.

Microscopy and localization. All imaging was performed on an Olympus IX81 confocal scope. Transcriptional and rescuing translational $g f p$ transgenes for tyra-3a::gfp, tyra-3a::tyra-3a::GFP, and npr-10::gfp were constructed containing $\sim 5 \mathrm{~kb}$ upstream of the predicted tyra-3a or $n p r-10$ ATG or including sequence encoding for the full-length tyra-3a gene fused in-frame with GFP at the C terminus. Uptake of $1,1^{\prime}$ dioctadecyl-3,3,3', $3^{\prime}$-tetramethylindodicarbocyanine (DiD) to identify a subset of amphid sensory neurons was assayed as described previously (Herman and Hedgecock, 1990; Harris et al., 2010). To localize $n l p-14$ encoded neuropeptides in the ASIs, the gpa-4 promoter was fused to $m$ Cherry::rab-3::unc-54 3'UTR, and the gpa-4::mCherry::rab-3 construct was microinjected into $n l p-14$ mutant animals stably expressing a rescuing gpa-4::nlp-14::gfp transgene. Animals with/without gpa-4::mCherry::rab-3 were immobilized on agarose pads with $20 \mathrm{~mm}$ sodium azide and imaged for both GFP and mCherry fluorescence.

Phosphoinositide turnover. Phosphatidylinositol (PI) turnover was assayed as described previously (Tejada et al., 2006). Briefly, COS-7 cells were seeded into 12 -well plates and transiently transfected with pFLAGtyra-3a (500 ng) using Lipofectamine 2000 (Invitrogen). Twenty-four hours after transfection, cells were washed with $0.5 \mathrm{ml}$ of PBS, and $0.5 \mathrm{ml}$ of inositol-free DMEM supplemented with $25 \mathrm{~mm}$ L-glucose, $4 \mathrm{~mm}$ L-glutamine, $10 \%$ bovine calf serum, and $\left[{ }^{3} \mathrm{H}\right] \mathrm{Ins}(10 \mu \mathrm{Ci} / \mathrm{ml})$ was added to each well to a final concentration of $1 \mu \mathrm{Ci} / \mathrm{ml}$. Cells were radiolabeled overnight and then incubated for $1 \mathrm{~h}$ with ligand at $37^{\circ} \mathrm{C}$. Incubations were stopped by rapid removal of media and the addition of $350 \mu \mathrm{l}$ of ice-cold $50 \mathrm{~mm}$ formic acid, followed by incubation at room temperature for $20 \mathrm{~min}$. Yttrium silicate scintillation proximity assay beads $(1 \mathrm{mg} / 80$ $\mu \mathrm{l}$ in water) were added, followed by the addition $20 \mu \mathrm{l}$ of the formic acid cell extract. The plate was sealed and shaken for $1 \mathrm{~h}$ at $4^{\circ} \mathrm{C}$, and, after $2 \mathrm{~h}$ at $4^{\circ} \mathrm{C}$, radioactivity was determined using a TopCount NXT system. Activity is presented as percentage activation above basal.

\section{Results}

TYRA-3 functions in dopaminergic, octopaminergic, and peptidergic neurons to inhibit the 5-HT stimulation of ASHmediated aversive responses

Aversive responses mediated by the two ASH sensory neurons are modulated extensively by nutritional state. For example, when a hair dipped in dilute (30\%) 1-octanol is placed in front of animal moving forward, backward locomotion is initiated in $\sim 10 \mathrm{~s}$ under basal conditions off food and in $\sim 5 \mathrm{~s}$ on food or in the presence of 5-HT (Chao et al., 2004; Harris et al., 2009). In contrast, TA completely abolishes this food or 5-HT-dependent stimulation, i.e., in the presence of food or 5-HT and TA the animals initiate reversal in response to dilute octanol in $\sim 10 \mathrm{~s}$, suggesting that the circuit mediating ASH-dependent aversive responses might exist in two different, nutritionally dependent, activity states (Wragg et al., 2007; for discussion, see Komuniecki et al., 2012a; Fig. 1A). Previously, we demonstrated that the TA receptor TYRA-3 was essential for this TA inhibition of serotonergic stimulation (Wragg et al., 2007). For example, TA did not inhibit the food or 5-HT stimulation of aversive responses in tyra-3 null animals, although these animals still exhibited wildtype responses off food or in the presence of food or 5-HT (Wragg et al., 2007; Fig. 1B). In contrast, animals with null alleles for two other TA-dependent GPCRs, TYRA-2 or SER-2, or the TA-gated $\mathrm{Cl}^{-}$channel LGC-55 were still inhibited by TA (Rex et al., 2004, 2005; Pirri et al., 2009; Fig. 1B). As predicted, TA inhibition in the tyra-3 null animals could be rescued by the expression of a fulllength tyra-3 genomic transgene, and the overexpression of this tyra-3 transgene in wild-type animals in the absence of TA significantly inhibited the 5-HT stimulation of aversive responses (Wragg et al., 2007; Fig. 1B). TYRA-3 appears to be expressed as multiple isoforms from multiple promoters (Bendesky et al., 2011). Therefore, to functionally localize tyra-3 expression, tyra-3a transcriptional and rescuing translational $g f p$ transgenes were constructed that contained $\sim 5 \mathrm{~kb}$ upstream of the predicted tyra-3a ATG and included all of the sequence used previously to functionally localize tyra-3b expression (Bendesky et al., 2011). GFP fluorescence was observed in the ASK, AIM, AVA, BAG, CEP, OLQ, and SDQR neurons (Fig. $1 C-E$ ). These results agree with those reported for the tyra-3b::gfp transcriptional fusion but include additional expression in the RIC and ASI neurons (Bendesky et al., 2011). To identify the neurons involved in the TYRA-3-dependent TA inhibition of 5-HT-stimulated aversive responses, neuron-selective RNAi was used to knockdown tyra-3 expression (Fig. $1 F$ ). The RNAi knockdown of tyra-3 in the eight dopaminergic neurons, the two octopaminergic RIC interneurons, or the two peptidergic ASI sensory neurons abolished TA inhibition (Fig. $1 F$ ). In contrast, RNAi from an array of additional promoters expressed in other neurons had no effect on TA inhibition (Fig. 1F). Together, these data suggest that TYRA-3 functions in multiple neurons to inhibit the 5-HT stimulation of aversive behavior. 


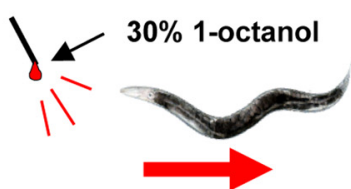

On food or 5-HT: fast ( $5 \mathrm{sec})$ Off food: slow ( $10 \mathrm{sec})$ On 5-HT AND TA: slow ( 10sec)
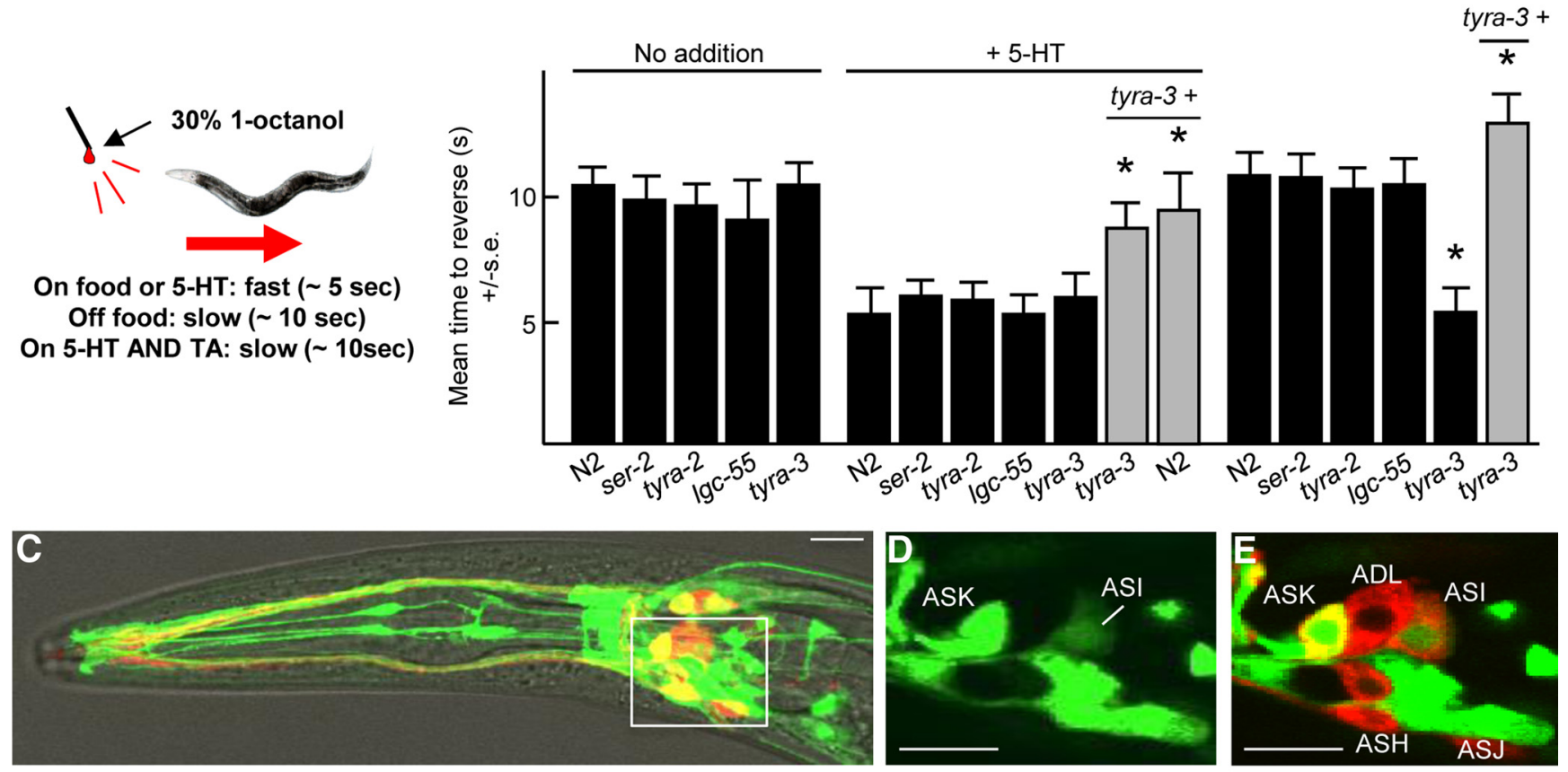

$\mathbf{F}$

$30 \% 1$-octanol $+5-\mathrm{HT}+\mathrm{TA}$

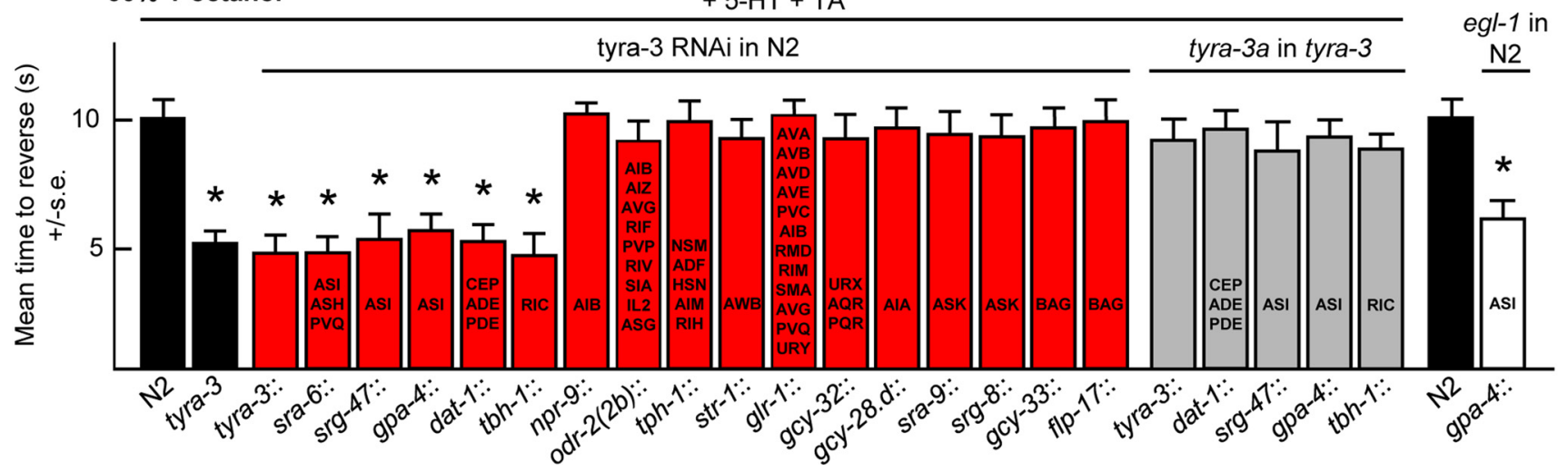

Figure 1. TYRA-3 functions in the octopaminergic RIC, dopaminergic ADE/CEP, and peptidergic ASI sensory neurons to inhibit 5-HT stimulated aversive behavior. $\boldsymbol{A}$, Model for aversive assay. $\boldsymbol{B}$, F, Aversive responses to $30 \%$ 1-octanol were assayed with or without 5-HT \pm TA in wild-type, mutant, or transgenic animals expressing either transgenes or RNAi. Black bars, Wild-type or null animals; gray bars, null animals expressing a rescuing transgene; red bars, wild-type animals expressing RNAi; white bars, wild-type animals expressing egl-1, with the promoters indicated. Data are presented as mean \pm SE and analyzed by two-tailed Student's $t$ test. ${ }^{*} p<0.001$, significantly different from wild-type animals under identical conditions. $\boldsymbol{C}-\boldsymbol{E}$, Fluorescence from wild-type animals expressing a tyra-3a::gfp transcriptional reporter by confocal microscopy. Scale bar, $10 \mu \mathrm{m}$. C, Merge of GFP fluorescence, DiD staining, and DIC. D, E, z-Section from inset in C. E, Merge of GFP and DiD staining.

To confirm these RNAi results, a tyra-3a::gfp was expressed in tyra-3 null animals from these same promoters (Fig. $1 F$ ). Surprisingly, tyra-3a expression in the dopaminergic, octopaminergic, or ASI neurons alone rescued TA inhibition (Fig. $1 F$ ). How could tyra-3 RNAi knockdown in one pair of neurons in wild-type animals abolish TA inhibition, whereas overexpression in a different pair of neurons rescue TA inhibition in tyra-3 null animals? We have also observed this phenomenon previously for the OA inhibition of aversive responses to $100 \% 1$-octanol and have discussed this apparent paradox extensively (Mills et al., 2012b). Monoamines appear to be released both tonically and acutely to activate a variety of extrasynaptic receptors on multiple neurons, suggesting that changing humoral concentrations of monoamines may, at least in part, define behavioral state. The composition of these extrasynaptic monoamines is dependent on contributions from multiple neurons, suggesting that small increases or decreases in ligand release from any one pair of neurons has the potential to alter signaling. Indeed, only twofold changes in the expression level of tyra-3 in the ASK and BAG sensory neurons can have profound effects on sensorymediated decision-making, suggesting that any overexpression in rescued animals (which is likely) may have the potential to compensate for the absence of release from other neurons (Bendesky et al., 2011). These data suggest that the activation of TYRA-3 may stimulate the release of DA, OA, and neuropeptides that together inhibit the 5-HT stimulation of ASH-mediated aversive responses; however, signaling from these neurons could also involve other signaling molecules or even gap junctions.

TYRA-3 stimulates the release of multiple inhibitory peptides from the ASI sensory neurons

TYRA-3-mediated signaling in the ASIs inhibited the 5-HT stimulation of aversive responses and ablation of the ASIs by the neuron- 
A

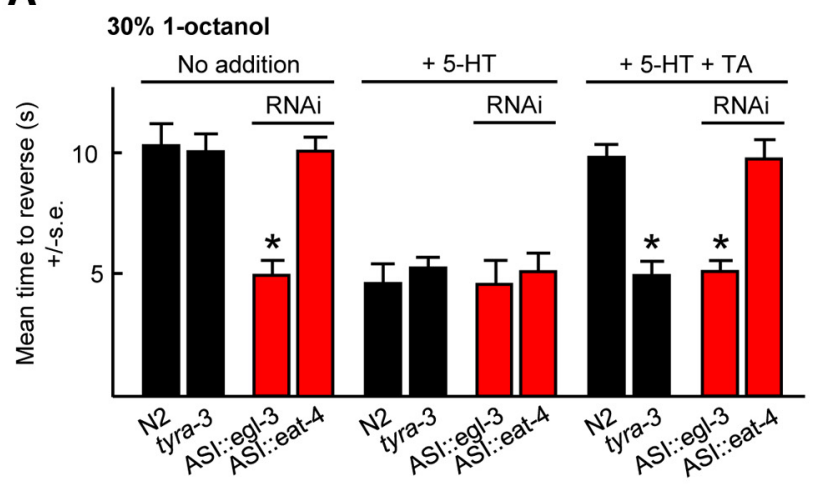

C $30 \%$ 1-octanol

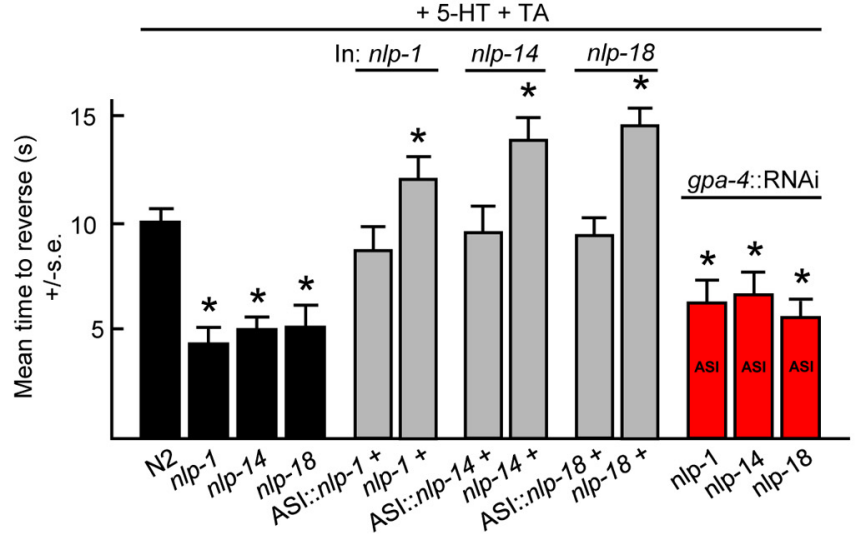

B

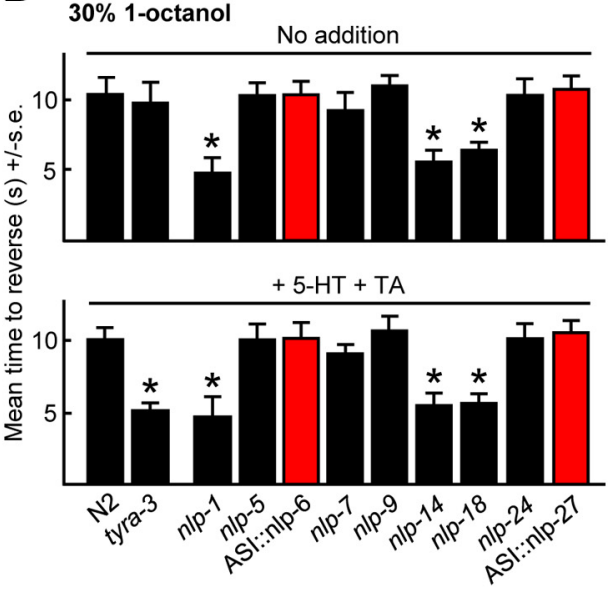

D

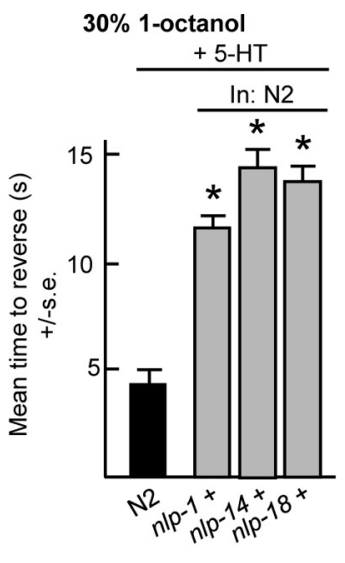

Figure 2. ASI peptidergic signaling is essential for the TA inhibition of 5 -HT-stimulated aversive responses. $A-D$, Wild-type or mutant animals expressing the designated transgenes or RNAis were assayed for aversive responses to 30\% 1-octanol with 5-HT \pm TA. Black bars, Wild-type or null animals; gray bars, wild-type or null animals expressing a transgene; red bars, RNAi in wild-type animals, with promoters indicated. Data are presented as mean \pm SE and analyzed by two-tailed Student's $t$ test. ${ }^{*} p<0.001$, significantly different from wild-type animals under identical conditions.

selective expression of EGL-1 that encodes a programmed cell death activator significantly reduced TA inhibition, suggesting that tonic signaling from the ASIs was inhibiting aversive responses (Fig. 1F; Conradt and Horvitz, 1998). To identify the ASI signaling molecules involved in TYRA-3 inhibition, ASI RNAi was used to knockdown the expression of eat-4, a vesicular glutamate transporter, and egl-3, a proprotein convertase required for peptide processing (Lee et al., 1999; Husson et al., 2006). Although this eat-4 RNAi has been used previously to knockdown expression and alter behavior in the ASH, ADL, and AWC sensory neurons, its expression in the ASIs had no effect on aversive responses, suggesting that ASI glutamatergic signaling was not involved in TA inhibition (Fig. 2A; Harris et al., 2010). In contrast, animals expressing ASI::egl-3 RNAi exhibited more rapid aversive responses off food and were not inhibited by TA, suggesting that TYRA-3 activated peptidergic signaling in the ASIs (Fig. 2A). To identify the ASI neuropeptide-encoding genes involved in TA inhibition, animals with null alleles for each ASI-expressed neuropeptide-encoding gene were examined for TA inhibition. $n l p-1, n l p-14$, or $n l p-18$ null animals all exhibited more rapid aversive responses off food than wild-type animals and were not inhibited by TA, suggesting that neuropeptides encoded by all three genes were essential for TA inhibition (Fig. 2B). More importantly, the ASI::RNAi knockdown of $n l p-1, n l p-14$, or $n l p-18$ also abolished the TA inhibition of 5-HT-stimulated aversive responses (Fig. 2C). Conversely, TA inhibition could be rescued in each of these neuropeptide null animals by the expression of the appropriate genomic or ASI- specific transgene (Fig. 2C), and animals overexpressing $n l p-1, n l p-$ 14 , or $n l p-18$ responded more slowly to dilute 1 -octanol in the presence of 5-HT than wild-type animals (Fig. 2D). Together, these data suggest that TYRA-3 stimulates the release of an array of neuropeptides from the ASIs that inhibit the 5-HT stimulation of aversive responses. Interestingly, the $n l p-1, n l p-14$, and $n l p-18$ null animals exhibited more rapid aversive responses off food, whereas the tyra-3 null animals did not, suggesting that multiple inputs may be regulating neuropeptide release from the ASIs or from other neurons expressing these same neuropeptides. Indeed, these neuropeptide-encoding genes are expressed in a wide array of additional neurons, suggesting that they play a broader role in locomotory decision-making (Li et al., 1999; Nathoo et al., 2001).

\section{NLP-14::GFP is localized to the synapses of the ASIs}

To localize the neuropeptides encoded by $n l p-14$ in the ASIs, an ASI::nlp-14::gfp transgene was stably expressed in $n l p-14$ null animals. A number of lines with varying amounts of ASI::NLP-14::GFP fluorescence were isolated. In lines that rescued the TA inhibition in nlp-14 null animals, but exhibited low levels of GFP fluorescence, robust fluorescence was observed in the ASI cell body and in seven to nine puncta in the distal portion of the ASI axonal process (Fig. 3A). Because the ASIs only contain approximately seven to nine synapses, also in the distal portion of the ASI axonal processes, we hypothesized that these puncta might be synaptic (White et al., 1986; Crump et al., 2001). Indeed, each of 

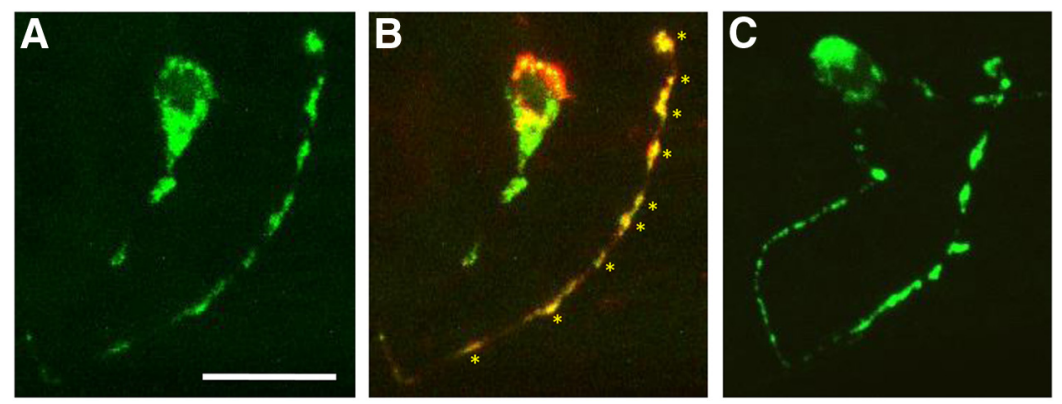

Figure 3. NLP-14::GFP is localized to synapses of the ASIs. Fluorescence from n/p-14 null animals expressing gpa-4::n/p-14::gfp translational fusions $(\boldsymbol{A}-\boldsymbol{C})$ coexpressed with gpa-4:::mCherry::rab-3 $(\boldsymbol{B})$ using confocal microscopy. Anterior is right and dorsal is up. Scale bar, $10 \mu \mathrm{m} . \boldsymbol{B}$, Colocalization (yellow) of NLP-14::GFP (green) with the synaptic protein mCherry::RAB-3 (red) in an ASI neuron. Asterisks indicate colocalization along synapse-rich regions of the distal portion of an ASI axon. C, An nIp-14 mutant animal overexpressing gpa-4::n/p-14:::gfp, based on behavioral assays. NLP-14::GFP fluorescence (green) is observed in the ASI cell body and in additional puncta along the proximal portion of the ASI axon.

the NLP-14::GFP fluorescent puncta colocalized with ASI:: mCherry::RAB-3, a well-characterized presynaptic marker (Nonet et al., 1997; Graf et al., 2009; Fig. 3B). In contrast, animals overexpressing ASI::NLP-14::GFP, as evidenced by their slower responses to dilute octanol than wild-type animals in the presence of 5-HT ( 7-9 vs 5 s), exhibited additional smaller fluorescent puncta in the proximal portion of the ASI axonal processes, suggesting that these puncta might represent the trafficking of NLP-14::GFP (Fig. 3C). Together, these data suggest that $n l p-14$ encoded peptides are released synaptically.

TYRA- 3 couples to $\mathrm{G} \boldsymbol{\alpha}_{\mathrm{q}}$, and both ASI G $\alpha_{\mathrm{q}}$ and $\mathrm{G} \boldsymbol{\alpha}_{\mathrm{s}}$ signaling are required for TA inhibition

To understand the role of TYRA-3 signaling in modulating neuropeptide release from the ASIs, we examined (1) G-protein signaling in cells heterologously expressing TYRA-3 and (2) the role of ASI G-protein signaling in modulating TA inhibition.

COS-7 cells expressing TYRA-3 exhibited a marked TA-dependent increase in phosphoinositide turnover, with an $\mathrm{EC}_{50}$ of $70.8 \pm 7.4 \mathrm{nM}$ (Fig. $4 A, B$ ). In contrast, $\mathrm{OA}$ and DA had minimal and no effect, respectively (Fig. $4 A$ ). These data suggest that TA-dependent activation of TYRA-3 increased $\mathrm{G} \alpha_{\mathrm{q}}$ signaling, in agreement with reports for a related Drosophila TA receptor that specifically activated $\mathrm{Ca}^{2+}$-dependent $\mathrm{Cl}^{-}$channels when expressed in Xenopus oocytes (Cazzamali et al., 2005; Wragg et al., 2007).

To examine ASI G-protein signaling directly, we used a neuron-specific RNAi approach to either selectively increase or decrease ASI $\mathrm{G} \alpha_{\mathrm{q}}$ or $\mathrm{G} \alpha_{\mathrm{s}}$ signaling, as we described previously for the ASHs (Harris et al., 2010). The ASI RNAi knockdown of either gsa-1 $\left(\mathrm{G} \alpha_{\mathrm{s}}\right)$ or egl-30 $\left(\mathrm{G} \alpha_{\mathrm{q}}\right)$ significantly reduced the TA inhibition of 5-HT-stimulated aversive responses (Fig. 4C). Conversely, increasing either $\mathrm{G} \alpha_{\mathrm{s}}$ or $\mathrm{G} \alpha_{\mathrm{q}}$ signaling by the ASI RNAi knockdown of $p d e-4$ that encodes a phosphodiesterase responsible for cAMP degradation or $d g k-1$ that encodes a diacylglycerol kinase responsible for the catabolism of diacylglycerol, a key intermediate in $\mathrm{G} \alpha$ q signaling, significantly reduced the 5-HT stimulation of aversive responses (Fig. $4 C$ ). Together, these results suggest that both $\mathrm{G} \alpha_{\mathrm{q}}$ and $\mathrm{G} \alpha_{\mathrm{s}}$ signaling in the ASIs are required for TA inhibition and agree with recent reports from Drosophila motoneurons in which OA-evoked peptide release required the synergistic interaction of PKA and ER calcium signaling (Shakiryanova et al., 2011). Together, these data suggest that TYRA-3 signals through $\mathrm{G} \alpha_{\mathrm{q}}$ and that both $\mathrm{G} \alpha_{\mathrm{s}}$ and $\mathrm{G} \alpha_{\mathrm{q}}$ are required for ASI neuropeptide release.
Peptides encoded by $n l p-1$ and $n l p-14$ activate NPR-11 and NPR-10, respectively, to mediate TYRA-3dependent inhibition

To identify the GPCRs activated by neuropeptides encoded by $n l p-1, n l p-14$, and $n l p-18$, TA inhibition was examined in predicted neuropeptide receptor null animals. Initially, each of the $>50$ putative neuropeptide receptor null animals was examined in a variety of behavioral assays to develop a "fingerprint" that could be associated with null alleles for each of the neuropeptide-encoding genes, on the assumption that neuropeptide and cognate receptor null animals would exhibit similar phenotypes, as described previously for neuropeptides encoded by $n l p-3$, $n l p-8$, and $n l p-9$ (Harris et al., 2010; Mills et al., 2012a). For example, predicted neuropeptide receptor null animals that exhibited wild-type aversive responses on food and 5-HT that were also inhibited by OA, as previously observed for $n l p-1, n l p-14$, and $n l p-18$ null animals, were examined for TA inhibition (Fig. 5A). 5-HT-stimulated aversive responses were not inhibited by TA in animals with putative null alleles for $n \mathrm{pr}$ 10, npr-11, and f41e7.3 (Fig. 5A). Importantly, NPR-11 had been identified previously as a receptor for neuropeptides encoded by $n l p-1$, validating our approach (Chalasani et al., 2010). Next, $n l p-14$ or $n l p-18$, were overexpressed in the $n p r-10$ and f41e7.3 null backgrounds, on the assumption that the inhibition of 5-HT-stimulated aversive responses observed by $n l p-14$ or $n l p-18$ overexpression in wild-type animals would be absent or significantly reduced in animals lacking their cognate receptors, as described previously (Harris et al., 2010; Mills et al., 2012a). The overexpression of $n l p-14$ in $n p r-10$ null animals failed to inhibit 5-HT stimulation, suggesting that NPR-10 encoded a receptor for neuropeptides encoded by $n l p-14$ (Fig. $5 B$ ). As predicted, the expression of $n p r-10$ or $n p r-11$ in the appropriate null animals rescued TA inhibition (Fig. $5 C$ ). Together, these data suggest that peptides encoded by $n l p-1$ activate NPR-11 and those encoded by nlp-14 activate NPR-10 to inhibit 5-HT-stimulated aversive responses.

To functionally localize NPR-10 and NPR-11 in the TAdependent pathway inhibiting aversive responses, the promoter:: GFP, neuron-selective RNAi and rescue approach described above to localize TYRA-3 was used. A npr-10::gfp transgene was expressed robustly in body wall muscle and to a lesser extent in a number of head neurons, including the ASI and ADL sensory neurons and RIA interneurons (Fig. 6A, $B$ ). The RNAi knockdown of npr-10 in the ADLs, but not the ASIs, RIAs, or body wall muscle, significantly reduced the TA inhibition of 5-HT-stimulated aversive responses (Fig. 6C). Conversely, TA inhibition was rescued in $n p r-10$ null animals by the expression of ADL::npr-10::gfp and the overexpression of ADL::npr-10::gfp alone in wild-type animals abolished 5-HT stimulation (Fig. 6C). Similarly, the expression of an $n p r-11:: g f p$ in the AIA interneurons has been reported previously and the RNAi knockdown of npr-11 in the AIA interneurons abolished TA inhibition, whereas the expression of NPR-11 in the AIAs rescued TA inhibition in npr-11 null animals (Fig. 6D; Chalasani et al., 2010). Together, these data suggest that neuropeptides encoded by $n l p-1$ activate NPR-11 
A

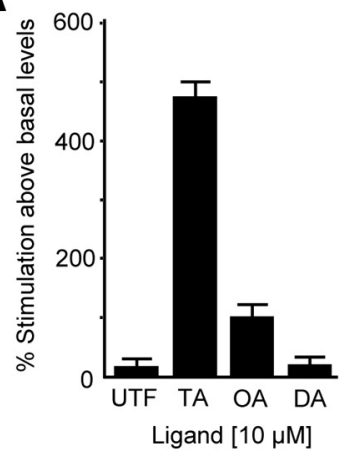

B

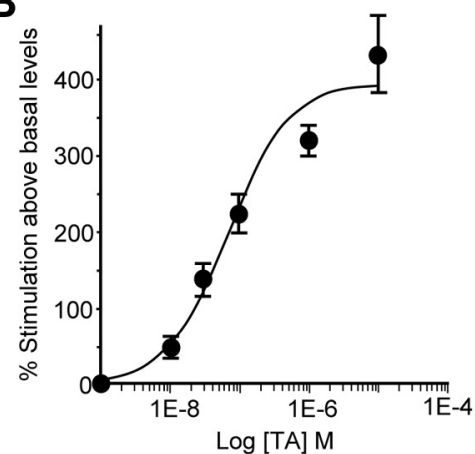

C

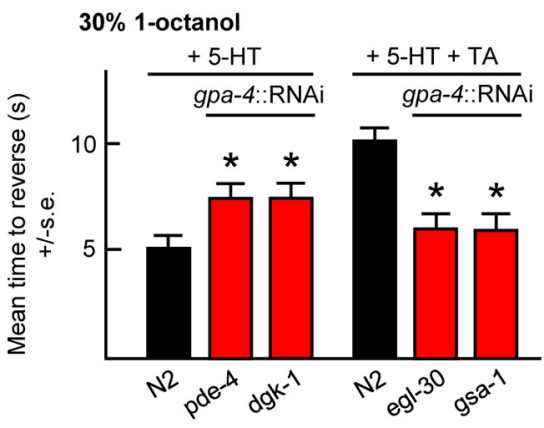

Figure 4. TYRA-3 couples to $\mathrm{G} \alpha_{q}$ and both $G \alpha_{q}$ and $G \alpha_{s}$ signaling in the ASIs are required for TA inhibition. $A, B$, TA stimulates phosphoinositide metabolism in COS-7 cells expressing TYRA-3a. COS-7 cells transiently transfected with TYRA-3a-pFLAG were labeled with $\left[{ }^{3} \mathrm{H}\right]$ inositol and incubated with various monoamines at $[10 \mu \mathrm{m}](\boldsymbol{A})$ or TA at a range of concentrations $(\boldsymbol{B})$. PI turnover was assayed according to Tejada et al. (2006). Values are expressed as percentage stimulation above basal. C, Wild-type and transgenic animals expressing cell-specific RNAi were assayed for aversive responses to 30\% 1-octanol with 5-HT \pm TA. Black bars, Wild-type animals; red bars, RNAi in wild-type animals. Data are presented as mean \pm SE and analyzed by two-tailed Student's $t$ test. ${ }^{*} p<0.001$, significantly different from wild-type animals examined under identical conditions.

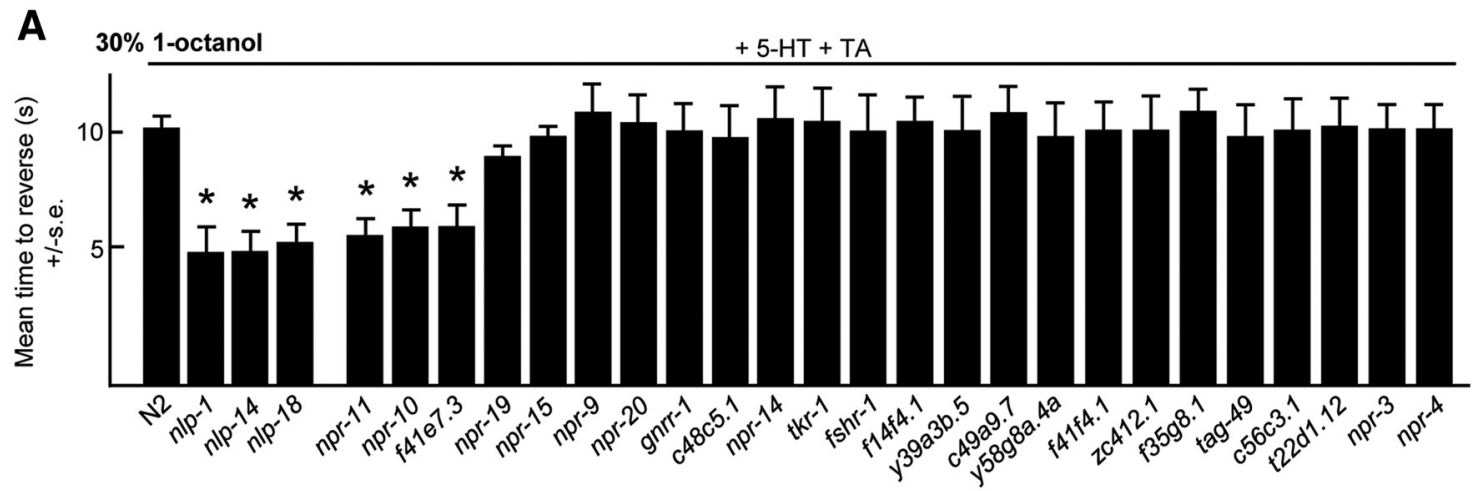

B $30 \%$ 1-octanol

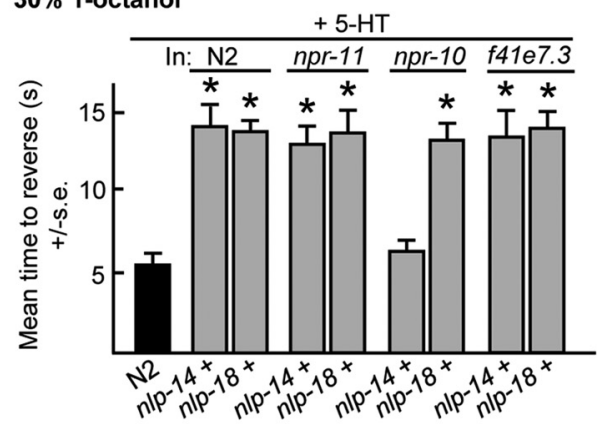

C $30 \%$ 1-octanol

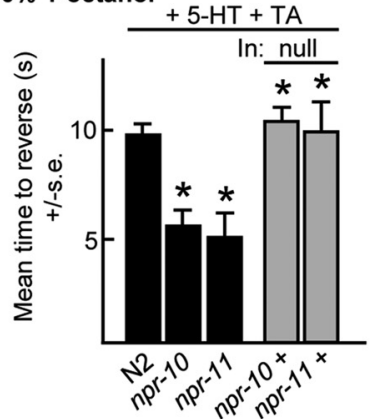

Figure 5. Identification of potential ligands for the neuropeptide receptors involved in the TA inhibition of 5-HT-stimulated aversive responses. $A$, Putative neuropeptide receptor null mutants were assayed for aversive responses to 30\% 1-octanol in the presence of exogenous 5-HT and TA. B, C, Animals overexpressing individual neuropeptide-encoding genes or receptors in wild-type and mutant backgrounds were examined for aversive responses with 5-HT \pm TA. Black bars, Wild-type or null animals; gray bars, wild-type or null animals expressing a transgene. Data are presented as mean \pm SE and analyzed by two-tailed Student's $t$ test. ${ }^{*} p<0.001$, significantly different from wild-type animals examined under identical conditions.

in the AIA interneurons and those encoded by $n l p-14$ activate NPR-10 in the ADL sensory neurons.

Signaling from the sensory neurons innervated by the ASIs can modulate ASH-mediated aversive responses

The results outlined above and from previous studies suggest that peptidergic signaling from the ASIs to the glutamatergic ADLs, AWCs, or ASER sensory neurons has the capacity to inhibit ASHmediated aversive responses, based on the localization of the cognate neuropeptide receptors (Mills et al., 2012a; Ohnishi et al., 2011). Therefore, to examine the roles of ADL, AWC, or ASER signaling on ASH-mediated aversive responses directly, the vesicular glutamate transporter encoded by eat-4 was selectively overexpressed in the ADLs, AWCs, or ASER/ASEL, on the assumption that eat-4 overexpression would selectively increase glutamatergic signaling from these neurons. As a control, eat-4 was also overexpressed in the ASHs. As predicted, eat-4 overexpression in the ASHs decreased the time taken to initiate reversal off food in response to $30 \% 1$-octanol from $\sim 10$ to $5 \mathrm{~s}$ (Fig. 7). It is unclear whether ASH::eat-4 overexpression increases quantal content and/or vesicle number, but in similar experiments in Drosophila, both parameters appeared to be increased (Daniels et al., 2004, 2011). More importantly, eat-4 overexpression in both ADLs or ASEs, or ASER alone, also decreased the time taken to 

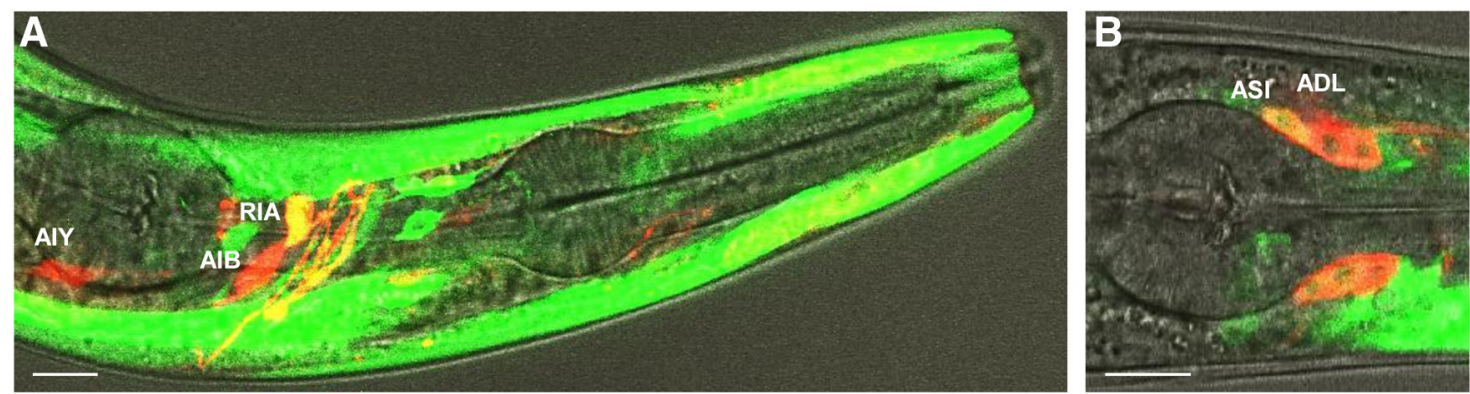

$30 \%$ 1-octanol

$30 \%$ 1-octanol
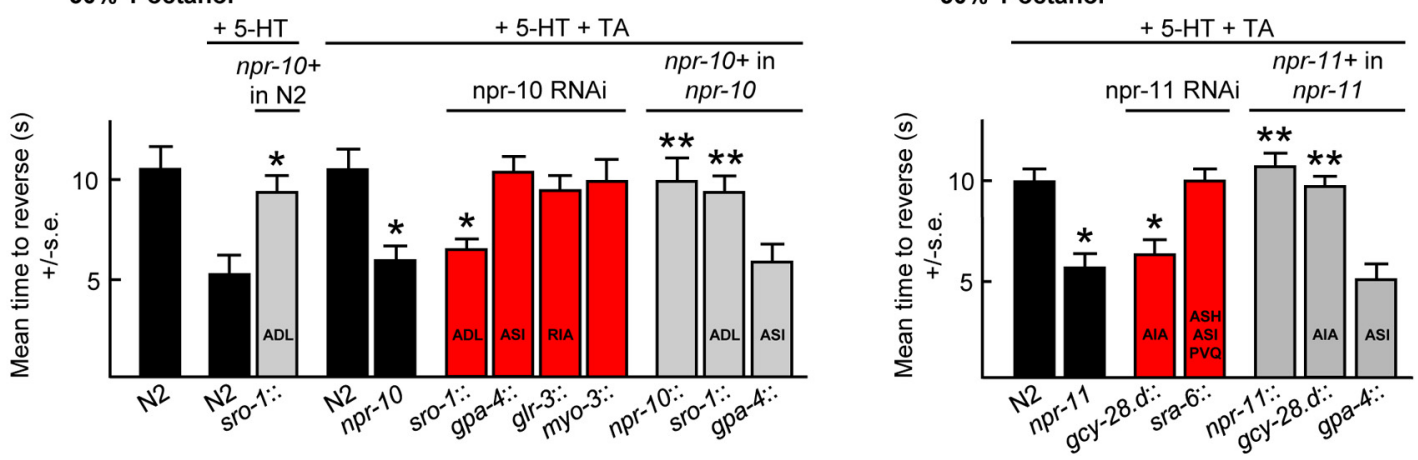

Figure 6. NPR-10 and NPR-11 function in the ADL and AIA neurons, respectively, to modulate the TA inhibition of 5-HT-stimulated aversive responses. $\boldsymbol{A}, \boldsymbol{B}$, Fluorescence from N2 wild-type animals expressing an npr-10::gfp transgene (containing $5 \mathrm{~kb}$ upstream of the predicted npr-10 ATG and genomic sequence encoding through to the second exon fused to GFP) using confocal microscopy. Scale bar, $10 \mu \mathrm{m}$. A, Colocalization (yellow) of the anterior portion of an animal expressing $n p r-10:: g f p$ and coexpressing ttx-3::rfp, npr-9::rfp, or glr-3::rfp for identification of AIY, AIB, and RIA neurons, respectively. B, Merge of GFP fluorescence, DiD, and DIC. C, D, Aversive responses to 30\% 1-octanol were assayed in wild-type, mutant, and transgenic animals with 5-HT \pm TA. Black bars, Wild-type or null animals; gray bars, null animals expressing a transgene; red bars, RNAi in wild-type animals with promoters indicated. Data are presented as mean \pm SE and analyzed by two-tailed Student's $t$ test. ${ }^{*} p<0.001$, significantly different from wild-type animals under identical conditions; ${ }^{* *} p<0.001$, significantly different from null animals under identical conditions.

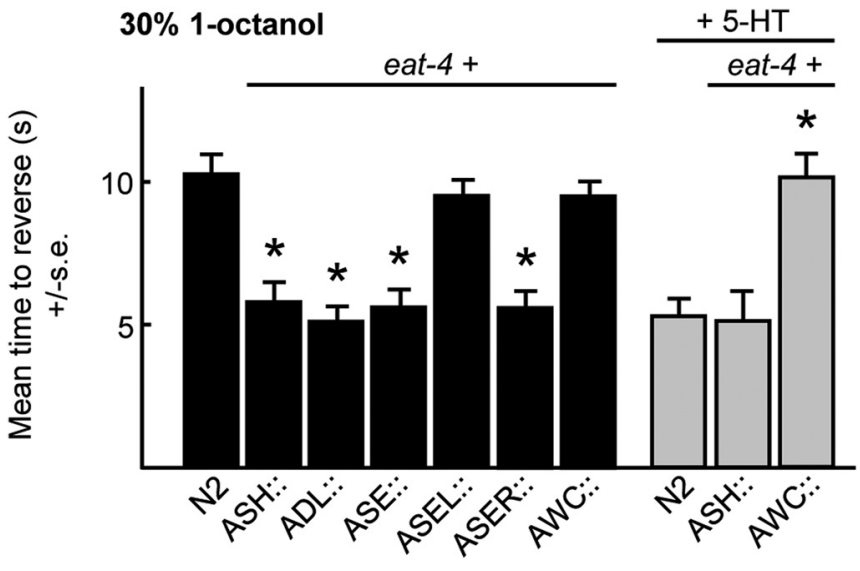

Figure 7. Glutamatergeric signaling from an array of sensory neurons has the potential to modulate ASH-mediated aversive responses. Wild-type or animals overexpressing eat- 4 were assayed for aversive responses to $30 \%$ 1-octanol \pm 5 -HT. Black bars, Wild-type; gray bars, wild-type animals expressing eat-4 from neuron-specific promoters. Data are presented as mean \pm SE and analyzed by two-tailed Student's $t$ test. ${ }^{*} p<0.001$, significantly different from wild-type animals under identical conditions.

initiate reversal off food, suggesting that ASI peptidergic signaling might be inhibiting signaling from these neurons (Fig. 7). In contrast, eat-4 overexpression in both AWCs had no effect on basal aversive responses off food but abolished 5-HT stimulation, suggesting that ASI peptidergic signaling might be stimulating signaling from the AWCs (Fig. 7). Indeed, as predicted, AWC::eat-4 RNAi increased aversive responses off food, supporting the hypothesis that AWC signaling tonically inhibited ASH-mediated aversive responses (Mills et al., 2012a). Together, these data support the hy- pothesis that the peptidergic modulation of signaling from an array of additional sensory neurons that respond to other environmental variables, including food odors, $\mathrm{CO}_{2}$, and salt, has the potential to modulate ASH-mediated aversive responses, just as inputs from multiple sensory neurons appear to fine tune adaptive food-leaving behavior (Chalasani et al., 2007, 2010; Bretscher et al., 2011; Milward et al., 2011).

\section{Discussion}

The present study demonstrates that the monoaminergic modulation of nociception mediated by the two ASH sensory neurons is complex and involves, in part, the TA-dependent activation of global monoaminergic and neuropeptidergic signaling cascades. Interestingly, the inhibition of ASH-mediated aversive responses by OA exhibits a similar complexity, with different OA receptors involved at different levels of ASH excitation (Mills et al., 2012a; Komuniecki et al., 2012a). Together, these studies highlight the similarities between the tyraminergic/octopaminergic inhibition of nociception in $C$. elegans and the noradrenergic inhibition of nociception in mammals that requires both direct inhibition of afferent nociceptors and the more global activation of inhibitory peptidergic signaling (Fairbanks et al., 2002; Kawasaki et al., 2003; Komuniecki et al., 2012a). Because most TA and OA receptors are expressed on neurons not directly innervated by the RIMs or RICs, responsible for TA and OA release, respectively, the majority of tyraminergic and octopaminergic signaling appears to be humoral, emphasizing the limitations of the wiring diagram in understanding nutritional modulation (Fig. 8; Bargmann, 2012). In contrast, monoamine-dependent peptidergic signaling appears to be primarily synaptic, based on the localization of the key peptide receptors to downstream synaptic partners of the peptidergic neurons 
(Fig. 8). For example, the ASIs appear to be presynaptic to only nine pairs of neurons, but each of the receptors activated by ASI neuropeptides has been functionally localized to at least one of these downstream neurons, i.e., NPR-11 (AIAs), NPR-10 (ADLs), and NPR-18 (ASER) (Chalasani et al., 2010; Mills et al., 2012a). Overall, these studies suggest that a broad, humorally translated, monoaminergic signal is both amplified and focused by the synaptic (or perisynaptic) release of distinct neuropeptides.

\section{Modest changes in TYRA-3 signaling may have dramatic effects on locomotory behavior}

Small changes in tyra-3 expression can initiate dramatic alterations in behavior. For example, only twofold changes in tyra-3 expression in the ASKs were sufficient to increase retention on a bacterial lawn (Bendesky et al., 2011). This study highlights the complexity of tyraminergic modulation, i.e., small changes in TA levels have the potential to significantly alter locomotory behavior. TA receptors are expressed as multiple isoforms, although their tissue specificity and functional differences have not been characterized (Rex et al., 2004, 2005; Bendesky et al., 2011; WormBase). For example, TYRA-3 is expressed from three distinct promoters as different isoforms with different $\mathrm{N}$ termini (Bendesky et al., 2011). Interestingly, similar tyra-3 isoforms in the parasitic nematode Ascaris suum exhibit differences in stage-specific expression during larval hepato-pulmonary migration (Komuniecki et al., 2012b). Overall, these studies highlight the flexibility of individual behaviors and the potential for their rapid, monoaminemediated, modulation by transient changes in the environment.

\section{TYRA-3 signaling may stimulate the release of both OA and} DA to inhibit ASH-mediated aversive behavior

TYRA-3 stimulates both octopaminergic and dopaminergic neurons, suggesting that TYRA-3 may stimulate the release of both DA and OA (Fig. 8). As predicted, exogenous DA and OA both inhibit the 5-HT stimulation of aversive responses and $t d c-1$, cat-2, or $t b h-1$ null animals, deficient in the synthesis of TA/OA, $\mathrm{DA}$, or OA, respectively, all exhibit more rapid basal aversive responses than wild-type animals, suggesting that TA, DA, and $\mathrm{OA}$ signaling tonically inhibit ASH-mediated aversive responses off food (Alkema et al., 2005; Wragg et al., 2007). Interestingly, both DA and OA modulate ASH signaling directly through antagonist pairs of DA or OA receptors on the ASHs. For example, exogenous $\mathrm{OA}$ at $4 \mathrm{~mm}$ abolishes 5-HT-stimulated aversive responses through an ASH-expressed, $\mathrm{G} \alpha_{\mathrm{o}}$-coupled OA receptor, OCTR-1, that appears to inhibit the release of both glutamate and stimulatory neuropeptides from the ASHs (Wragg et al., 2007; Mills et al., 2012a). In contrast, exogenous OA at $10 \mathrm{~mm}$ does not inhibit food or 5-HT stimulation, because at these elevated OA levels, a second ASH-expressed OA receptor, SER-3, antagonizes OCTR-1 signaling (Mills et al., 2012a). A similar antagonism appears to operate between DOP-3 and DOP-4 in the ASHs in the DA inhibition of food or 5-HT stimulation (Ezak and Ferkey,
2010; Ezcurra et al., 2011). Whether this type of antagonistic neuron-specific signaling is a generalized component of monoaminergic modulation remains to be determined, but both the G $\alpha_{\mathrm{q}}$-coupled TYRA-3 and the G $\alpha_{\mathrm{o}}$-coupled TA receptors TYRA-2 or SER-2 appear to be expressed in the ASIs and RICs, respectively (Tsalik et al., 2003; Rex et al., 2004).

\section{TA and OA stimulate the release of distinct and} non-overlapping pools of peptides from the ASIs

The TA inhibition of the food or 5-HT stimulation of aversive responses to 30\% 1-octanol requires TYRA-3 and ASI neuropeptides encoded by $n l p-1, n l p-14$, and $n l p-18$. In contrast, the OA inhibition of basal aversive responses to $100 \% 1$-octanol requires the OA receptor SER- 6 and ASI peptides encoded by $n l p-6, n l p-7$, and $n l p-9$ (Mills et al., 2012a). The ASI knockdown of $n l p-1$, $n l p-14$, and $n l p-18$ has no effect on OA inhibition, and, conversely, the ASI knockdown of $n l p-6, n l p-7$, or $n l p-9$ has no effect TA inhibition (Mills et al., 2012a). Together, these results suggest that the ASIs selectively release neuropeptides in response to TYRA-3 or SER-6 signaling, but the mechanism of this selective release is unclear. GPCR signaling in the axons of the RIAs appears to cause local $\mathrm{Ca}^{2+}$ increases that could potentially stimulate the release of large dense-core vesicles (LDCVs) at individual synapses, suggesting that the differential localization of TYRA-3 or SER-6 in the ASIs might explain selective release (Hendricks et al., 2012). In contrast, ASI neuropeptides might be selectively packaged into discrete populations of LDCVs and trafficked to different locations in the ASIs (Wang et al., 2010; Swanger and Bassell, 2011; Kindler and Kreienkamp, 2012). Alternatively, the neuropeptides might be selectively proteolyzed after release by specific neprilysins differentially expressed at sites of peptide re- 
lease (Turner et al., 2001; Isaac et al., 2009). Most peptides are synthesized as preproproteins that are processed through a multistep pathway (Smith et al., 1995; Rholam and Fahy, 2009). For example, precursors of mammalian neutrophilins, such as proNGF, are cleaved within the trans-Golgi network by a proprotein convertase, packaged into constitutive vesicles, and secreted continuously, whereas others such as the BNDF precursor are sorted into the regulated secretory pathway for secretion by a receptor-mediated mechanism, with activity-dependent secretion mediating many aspects of synaptic plasticity (Mizuno et al., 2000; Hibbert et al., 2003; Loh et al., 2004; Lu, 2004).

In summary, TA released in response to changing nutritional status activates a global monoaminergic/peptidergic signaling cascade, with receptors localized throughout the sensorymediated locomotory circuit (Fig. 8). The TYRA-3-mediated inhibition of ASH-mediated aversive responses appears to be primarily, if not exclusively, humoral, i.e., the tyraminergic RIMs do not synapse on the dopaminergic, octopaminergic, or peptidergic neurons activated by TYRA-3 and the octopaminergic RICs do not synapse directly on the ADL, AWB, and ASI neurons activated by OA and SER-6. In contrast, the peptidergic signaling involved in monoaminergic inhibition appears to be primarily synaptic (or perisynaptic) because the neuropeptide receptors have been functionally localized to downstream partners of the peptidergic neurons (Fig. 8). Together, these results suggest that monoaminergic nutritional signals released from a limited number of neurons are broadcast globally and amplified by more local peptidergic signaling to modulate not only locomotory decisionmaking but probably most nutritionally dependent behaviors in C. elegans. On a broader level, they highlight the obligate interaction between monoaminergic and peptidergic signaling in the complex, multilevel regulation of sensory-mediated behaviors.

\section{References}

Aimé P, Duchamp-Viret P, Chaput MA, Savigner A, Mahfouz M, Julliard AK (2007) Fasting increases and satiation decreases olfactory detection for a neutral odor in rats. Behav Brain Res 179:258-264. CrossRef Medline

Alkema MJ, Hunter-Ensor M, Ringstad N, Horvitz HR (2005) Tyramine functions independently of octopamine in the Caenorhabditis elegans nervous system. Neuron 46:247-260. CrossRef Medline

Bargmann CI (2012) Beyond the connectome: how neuromodulators shape neural circuits. Bioessays 34:458-465. CrossRef Medline

Bendesky A, Tsunozaki M, Rockman MV, Kruglyak L, Bargmann CI (2011) Catecholamine receptor polymorphisms affect decision-making in C. elegans. Nature 472:313-318. CrossRef Medline

Brenner S (1974) The genetics of Caenorhabditis elegans. Genetics 77:71-94. Medline

Bretscher AJ, Kodama-Namba E, Busch KE, Murphy RJ, Soltesz Z, Laurent P, de Bono M (2011) Temperature, oxygen, and salt sensing neurons in $C$. elegans are carbon dioxide sensors that control avoidance behavior. Neuron 69:1099-1113. CrossRef Medline

Cazzamali G, Klaerke DA, Grimmelikhuijzen CJ (2005) A new family of insect tyramine receptors. Biochem Biophys Res Commun 338:1189-1196. CrossRef Medline

Chalasani SH, Chronis N, Tsunozaki M, Gray JM, Ramot D, Goodman MB, Bargmann CI (2007) Dissecting a circuit for olfactory behaviour in Caenorhabditis elegans. Nature 450:63-70. CrossRef Medline

Chalasani SH, Kato S, Albrecht DR, Nakagawa T, Abbott LF, Bargmann CI (2010) Neuropeptide feedback modifies odor-evoked dynamics in Caenorhabditis elegans olfactory neurons. Nat Neurosci 13:615-621. CrossRef Medline

Chao MY, Komatsu H, Fukuto HS, Dionne HM, Hart AC (2004) Feeding status and serotonin rapidly and reversibly modulate a Caenorhabditis elegans chemosensory circuit. Proc Natl Acad Sci U S A 101:15512-15517. CrossRef Medline

Clifton PG, Kennett GA (2006) Monoamine receptors in the regulation of feeding behavior and energy balance. CNS Neurol Disord Drug Targets 5:293-312. CrossRef Medline
Conradt B, Horvitz HR (1998) The C. elegans protein EGL-1 is required for programmed cell death and interacts with the Bcl-2-like protein CED-9. Cell 93:519-529. CrossRef Medline

Crump JG, Zhen M, Jin Y, Bargmann CI (2001) The SAD-1 kinase regulates presynaptic vesicle clustering and axon termination. Neuron 29:115-129. CrossRef Medline

Daniels RW, Collins CA, Gelfand MV, Dant J, Brooks ES, Krantz DE, DiAntonio A (2004) Increased expression of the Drosophila vesicular glutamate transporter leads to excess glutamate release and a compensatory decrease in quantal content. J Neurosci 24:10466-10474. CrossRef Medline

Daniels RW, Miller BR, DiAntonio A (2011) Increased vesicular glutamate transporter expression causes excitotoxic neurodegeneration. Neurobiol Dis 41:415-420. CrossRef Medline

Drago A, Crisafulli C, Sidoti A, Serretti A (2011) The molecular interaction between the glutamatergic, noradrenergic, dopaminergic and serotonergic systems informs a detailed genetic perspective on depressive phenotypes. Prog Neurobiol 94:418-460. Medline

Esposito G, Di Schiavi E, Bergamasco C, Bazzicalupo P (2007) Efficient and cell specific knock-down of gene function in targeted C. elegans neurons. Gene 395:170-176. CrossRef Medline

Ezak MJ, Ferkey DM (2010) The C. elegans D2-like dopamine receptor DOP-3 decreases behavioral sensitivity to the olfactory stimulus 1-octanol. PLoS One 5:e9487. CrossRef Medline

Ezcurra M, Tanizawa Y, Swoboda P, Schafer WR (2011) Food sensitizes C. elegans avoidance behaviors through acute dopamine signaling. EMBO J 30:1110-1122. CrossRef Medline

Fairbanks CA, Stone LS, Kitto KF, Nguyen HO, Posthumus IJ, Wilcox GL (2002) alpha(2C)-Adrenergic receptors mediate spinal analgesia and adrenergic-opioid synergy. J Pharmacol Exp Ther 300:282-290. CrossRef Medline

Graf ER, Daniels RW, Burgess RW, Schwarz TL, DiAntonio A (2009) Rab3 dynamically controls protein composition at active zones. Neuron 64: 663-677. CrossRef Medline

Gray JM, Hill JJ, Bargmann CI (2005) A circuit for navigation in Caenorhabditis elegans. Proc Natl Acad Sci U S A 102:3184-3191. CrossRef Medline

Harris GP, Hapiak VM, Wragg RT, Miller SB, Hughes LJ, Hobson RJ, Steven R, Bamber B, Komuniecki RW (2009) Three distinct amine receptors operating at different levels within the locomotory circuit are each essential for the serotonergic modulation of chemosensation in Caenorhabditis elegans. J Neurosci 29:1446-1456. CrossRef Medline

Harris G, Mills H, Wragg R, Hapiak V, Castelletto M, Korchnak A, Komuniecki RW (2010) The monoaminergic modulation of sensory-mediated aversive responses in Caenorhabditis elegans requires glutamatergic/peptidergic cotransmission. J Neurosci 30:7889-7899. CrossRef Medline

Harris G, Korchnak A, Summers P, Hapiak V, Law WJ, Stein AM, Komuniecki P, Komuniecki R (2011) Dissecting the serotonergic food signal stimulating sensory-mediated aversive behavior in C. elegans. PLoS One 6:e21897. CrossRef Medline

Hendricks M, Ha H, Maffey N, Zhang Y (2012) Compartmentalized calcium dynamics in a C. elegans interneuron encode head movement. Nature 487:99-103. CrossRef Medline

Herman RK, Hedgecock EM (1990) Limitations of the size of the vulval primordium of Caenorhabditis elegans by lin-15 expression in surrounding hypodermis. Nature 348:169-171. CrossRef Medline

Hibbert AP, Morris SJ, Seidah NG, Murphy RA (2003) Neurotrophin-4, alone or heterodimerized with brain-derived neurotrophic factor, is sorted to the constitutive secretory pathway. J Biol Chem 278:48129-48136. CrossRef Medline

Hobert O (2002) PCR fusion-based approach to create reporter gene constructs for expression analysis in transgenic C. elegans. Biotechniques 32: 728-730. Medline

Husson SJ, Clynen E, Baggerman G, Janssen T, Schoofs L (2006) Defective processing of neuropeptide precursors in Caenorhabditis elegans lacking preproprotein convertase 2 (KPC/EGL-3): mutant analysis by mass spectrometry. J Neurochem 98:1999-2012. CrossRef Medline

Isaac RE, Bland ND, Shirras AD (2009) Neuropeptidases and the metabolic inactivation of insect neuropeptides. Gen Comp Endocrinol 162:8-17. CrossRef Medline

Kawasaki Y, Kumamoto E, Furue H, Yoshimura M (2003) Alpha 2 adrenoreceptor-mediated presynaptic inhibition of primary afferent glutamatergic transmission in rat substantia gelatinosa neurons. Anesthesiology 98:682-689. CrossRef Medline 
Kindler S, Kreienkamp HJ (2012) Dendritic mRNA targeting and translation. Adv Exp Med Biol 970:285-305. CrossRef Medline

Komuniecki R, Harris G, Hapiak V, Wragg R, Bamber B (2012a) Monoamines activate neuropeptide signaling cascades to modulate nociception in C. elegans: a useful model for the modulation of chronic pain? Invert Neurosci 12:53-61. CrossRef Medline

Komuniecki R, Law WJ, Jex A, Geldhof P, Gray J, Bamber B, Gasser RB (2012b) Monoaminergic signaling as a target for anthelmintic drug discovery: receptor conservation among the free-living and parasitic nematodes. Mol Biochem Parasitol 183:1-7. CrossRef Medline

Kramer JM, French RP, Park EC, Johnson JJ (1990) The Caenorhabditis elegans rol-6 gene, which interacts with the sqt-1 collagen gene to determine organismal morphology, encodes a collagen. Mol Cell Biol 10:2081-2089. Medline

Lee RY, Sawin ER, Chalfie M, Horvitz HR, Avery L (1999) EAT-4, a homolog of a mammalian sodium-dependent inorganic phosphate cotransporter, is necessary for glutamatergic neurotransmission in Caenorhabditis elegans. J Neurosci 19:159-167. Medline

Li C, Nelson LS, Kim K, Nathoo A, Hart AC (1999) Neuropeptide gene families in the nematode Caenorhabditis elegans. Ann N Y Acad Sci 897: 239-252. CrossRef Medline

Loh YP, Kim T, Rodriguez YM, Cawley NX (2004) Secretory granule biogenesis and neuropeptide sorting to the regulated secretory pathway in neuroendocrine cells. J Mol Neurosci 22:63-71. CrossRef Medline

Lu B (2004) Acute and long-term synaptic modulation by neurotrophins. Prog Brain Res 146:137-150. Medline

Magalhães CP, de Freitas MF, Nogueira MI, Campina RC, Takase LF, de Souza S, de Castro R (2010) Modulatory role of serotonin on feeding behavior. Nutr Neurosci 13:246-255. CrossRef Medline

Melcher C, Pankratz MJ (2005) Candidate gustatory interneurons modulating feeding behaviors in the Drosophila brain. PLoS Biol 3:e305. Medline

Mello C, Fire A (1995) DNA transformation. Methods Cell Biol 48:451482. CrossRef Medline

Mills H, Wragg R, Hapiak V, Castelletto M, Zahratka J, Harris G, Summers P, Korchnak A, Law W, Bamber B, Komuniecki R (2012a) Monoamines and neuropeptides interact to inhibit aversive behavior in Caenorhabditis elegans. EMBO J 31:667-678. CrossRef Medline

Mills H, Hapiak V, Harris G, Summers P, Komuniecki R (2012b) The interaction of octopamine and neuropeptides to slow aversive responses in C. elegans mimics the modulation of chronic pain in mammals. Worm 1:1-5. CrossRef

Milward K, Busch KE, Murphy RJ, de Bono M, Olofsson B (2011) Neuronal and molecular substrates for optimal foraging in Caenorhabditis elegans. Proc Natl Acad Sci U S A 108:20672-20677. CrossRef Medline

Mizuno M, Yamada K, Olariu A, Nawa H, Nabeshima T (2000) Involvement of brain-derived neurotrophic factor in spatial memory formation and maintenance in a radial arm maze test in rats. J Neurosci 20:7116-7121. Medline

Mulligan C, Moreau K, Brandolini M, Livingstone B, Beaufrère B, Boirie Y (2002) Alterations of sensory perceptions in healthy elderly subjects during fasting and refeeding. A pilot study. Gerontology 48:39-43. CrossRef Medline

Nathoo AN, Moeller RA, Westlund BA, Hart AC (2001) Identification of neuropeptide-like protein gene families in Caenorhabditis elegans and other species. Proc Natl Acad Sci U S A 98:14000-14005. CrossRef Medline

Negroni J, Meunier N, Monnerie R, Salesse R, Baly C, Caillol M, Congar P (2012) Neuropeptide Y enhances olfactory mucosa responses to odorant in hungry rats. PLoS One 7:e45266. CrossRef Medline

Nonet ML, Staunton JE, Kilgard MP, Fergestad T, Hartwieg E, Horvitz HR, Jorgensen EM, Meyer BJ (1997) Caenorhabditis elegans rab-3 mutant synapses exhibit markedly impaired function and are partially depleted of vesicles. J Neurosci 17:8061-8073. Medline

Ohnishi N, Kuhara A, Nakamura F, Okochi Y, Mori I (2011) Bidirectional regulation of thermotaxis by glutamate transmissions in Caenorhabditis elegans. EMBO J 30:1376-1388. CrossRef Medline
Pirri JK, McPherson AD, Donnelly JL, Francis MM, Alkema MJ (2009) A tyramine-gated chloride channel coordinates distinct motor programs of a Caenorhabditis elegans escape response. Neuron 62:526-538. CrossRef Medline

Prud'homme MJ, Lacroix MC, Badonnel K, Gougis S, Baly C, Salesse R, Caillol M (2009) Nutritional status modulates behavioral and olfactory bulb Fos responses to isoamyl acetate or food odour in rats: roles of orexins and leptins. Neuroscience 162:1287-1298. CrossRef Medline

Rex E, Molitor SC, Hapiak V, Xiao H, Henderson M, Komuniecki R (2004) Tyramine receptor (SER-2) isoforms are involved in the regulation of pharyngeal pumping and foraging behavior in Caenorhabditis elegans. J Neurochem 91:1104-1115. CrossRef Medline

Rex E, Hapiak V, Hobson R, Smith K, Xiao H, Komuniecki R (2005) TYRA-2 (F01E11.5): a Caenorhabditis elegans tyramine receptor expressed in the MC and NSM pharyngeal neurons. J Neurochem 94: 181-191. CrossRef Medline

Rholam M, Fahy C (2009) Processing of peptide and hormone precursors at the dibasic cleavage sites. Cell Mol Life Sci 66:2075-2091. CrossRef Medline

Root CM, Ko KI, Jafari A, Wang JW (2011) Presynaptic facilitation by neuropeptide signaling mediates odor-driven food search. Cell 145:133-144. CrossRef Medline

Sengupta P (2013) The belly rules the nose: feeding state-dependent modulation of peripheral chemosensory responses. Curr Opin Neurobiol 23: 68-75. CrossRef Medline

Shakiryanova D, Zettel GM, Gu T, Hewes RS, Levitan ES (2011) Synaptic neuropeptide release induced by octopamine without $\mathrm{Ca}^{2+}$ entry into the nerve terminal. Proc Natl Acad Sci U S A 108:4477-4481. CrossRef Medline

Smith MM, Shi L, Navre M (1995) Rapid identification of highly active and selective substrates for stromelysin and matrilysin using bacteriophage peptide display libraries. J Biol Chem 270:6440-6449. CrossRef Medline

Swanger SA, Bassell GJ (2011) Making and breaking synapses through local mRNA regulation. Curr Opin Genet Dev 21:414-421. CrossRef Medline

Tejada FR, Nagy PI, Xu M, Wu C, Katz T, Dorsey J, Rieman M, Lawlor E, Warrier M, Messer WS Jr (2006) Design and synthesis of novel derivatives of the muscarinic agonist tetra(ethylene glycol)(3-methoxy-1,2,5-thiadiazol-4-yl) [3-(1-methyl-1,2,5,6- tetrahydropyrid-3-yl)-1,2,5-thiadiazol-4-yl] ether (CDD-0304): effects of structural modifications on the binding and activity at muscarnic receptor subtypes and chimeras. J Med Chem 49:7518-7531. CrossRef Medline

Tsalik EL, Niacaris T, Wenick AS, Pau K, Avery L, Hobert O (2003) LIM homeobox gene-dependent expression of biogenic amine receptors in restricted regions if the C. elegans nervous system. Dev Biol 263:81-102. CrossRef Medline

Turner AJ, Isaac RE, Coates D (2001) The neprilysin (NEP) family of zinc metalloendopeptidases: genomics and function. Bioessays 23:261-269. CrossRef Medline

Wang HB, Zhao B, Zhong YQ, Li KC, Li ZY, Wang Q, Lu YJ, Zhang ZN, He SQ, Zheng HC, Wu SX, Hökfelt TG, Bao L, Zhang X (2010) Coexpression of delta- and mu-opiod receptors in nociceptive sensory neurons. Proc Natl Acad Sci U S A 107:13117-13122. CrossRef Medline

Werner FM, Conveñas R (2010) Classical neurotransmitters and neuropeptides involved in major depression: a review. Int J Neurosci 120:455-470. CrossRef Medline

White J, Southgate E, Thompson JN, Brenner S (1986) The structure of the nervous system of the nematode Caenorhabditis elegans. Philos Trans R Soc Lond B Biol Sci 314:1-340. CrossRef

Wragg RT, Hapiak V, Miller SB, Harris GP, Gray J, Komuniecki PR, Komuniecki RW (2007) Tyramine and octopamine independently inhibit serotonin-stimulated aversive behaviors in Caenorhabditis elegans through two novel amine receptors. J Neurosci 27:13402-13412. CrossRef Medline

Yeomans MR (2006) Olfactory influences on appetite and satiety in humans. Physiol Behav 89:10-14. CrossRef Medline 